\section{Detección temprana}

El cáncer de mama es curable... la detección temprana es clave.

En etapa temprana, tiene un pronóstico favorable con $\mathbf{9 5 \%}$ de supervivencia.

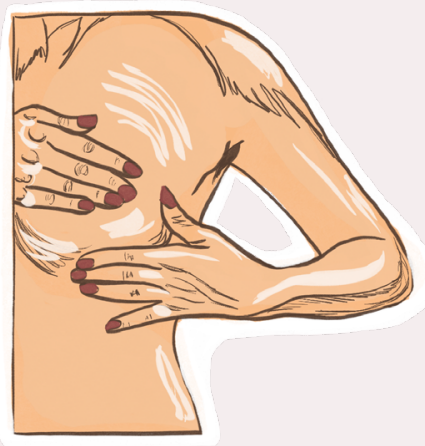

El conocimiento de su cuerpo es clave para identificar cambios en los senos y buscar una opinión médica.

\section{Signos sospechosos}
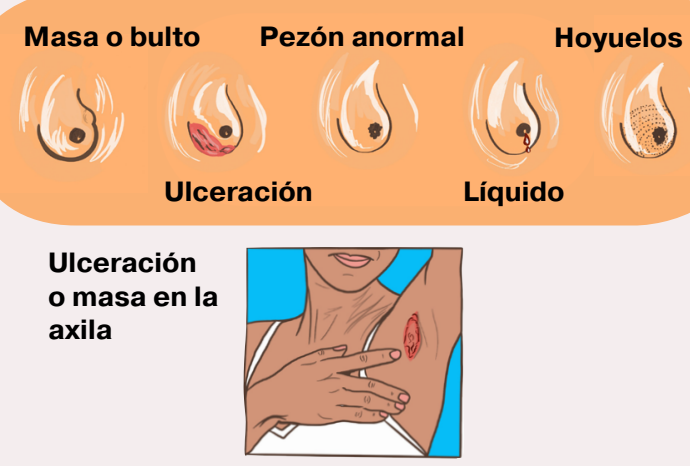

Se recomienda hacer mensualmente la autoexploración para identificar la presencia de signos sospechosos. Una vez al año se debe solicitar el examen clínico, a partir de los 25 años, y la mamografía a partir de los 40 años.

\section{Diagnóstico del cáncer de mama}

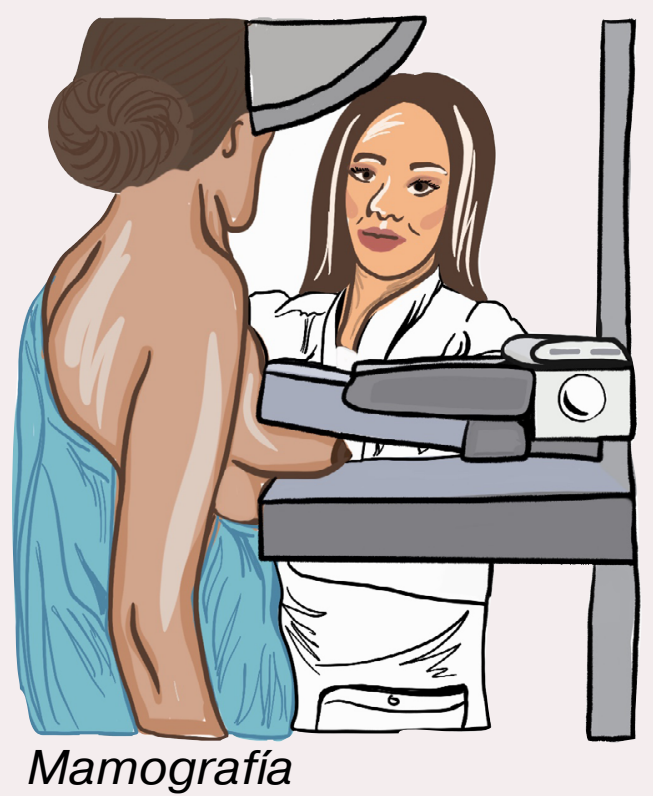

No todas las enfermedades que se presentan en el seno son malignas (cancerosas).

No debe tener temor si hay un tumor maligno porque el cáncer de mama es curable.

Solo en unidades médicas especializadas puede confirmarse el diagnóstico de cáncer de mama.

Es importante insistir en mantener una copia del resultado del estudio.

\section{Tratamiento}

El tratamiento oportuno aumenta la posibilidad de que el tratamiento sea menos agresivo y genere menos gastos económicos e impactos psicológicos y sociales.
El propósito es detener el progreso del cáncer y evitar que se disperse a otros órganos y tejidos.

El tratamiento para el cáncer depende del momento del diagnóstico (temprano o tardío), tamaño del tumor y tipo de riesgo (historia familiar) y puede incluir cirugía, quimioterapia, radioterapia y terapia hormonal.

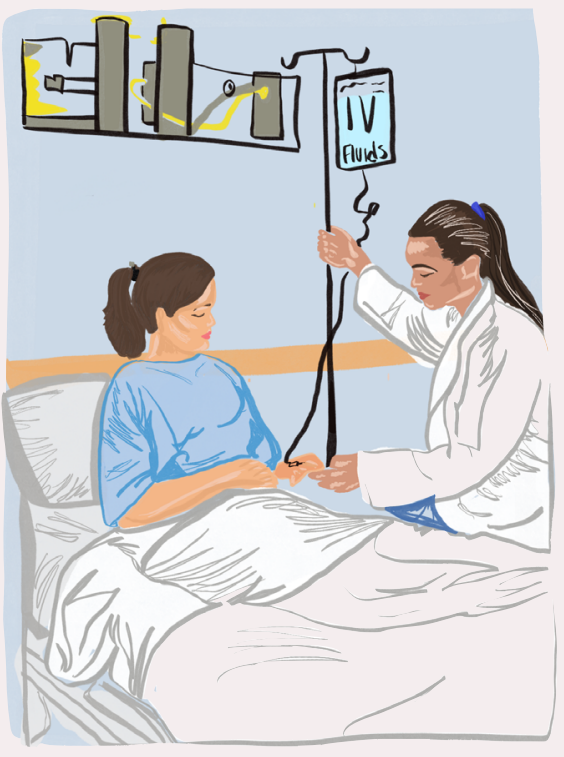

Todos los tratamientos pueden producir efectos secundarios que son manejables y se pueden sobrellevar con el apoyo médico, familiar y comunitario. 


\section{¿Qué es el cáncer de mama?}

Es el cáncer que se desarrolla a partir del tejido mamario. Se origina cuando las células en el seno comienzan a crecer en forma descontrolada y normalmente forman un tumor.

El tumor se puede observar en una radiografía o sentir como una masa o bulto.

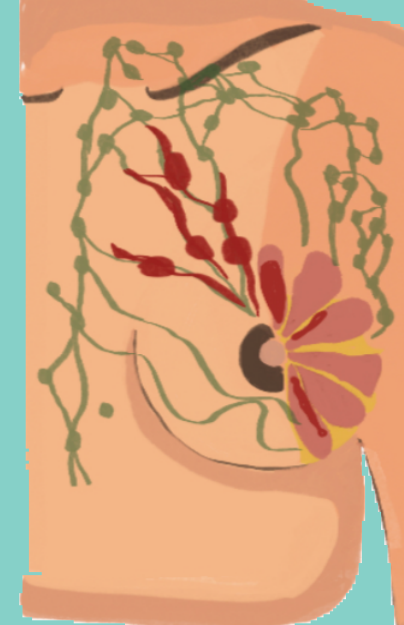

El cáncer de mama afecta a adultos de todas edades, sin distinción de nivel social, económico o educativo.

\section{Sobrevivencia}

Una persona es considerado un

sobreviviente del cáncer desde el momento del diagnóstico, durante e inmediatamente después del tratamiento, y a través del resto de su vida. El seguimiento con atención médica es primordial para minimizar los síntomas y el riesgo de recurrencia.

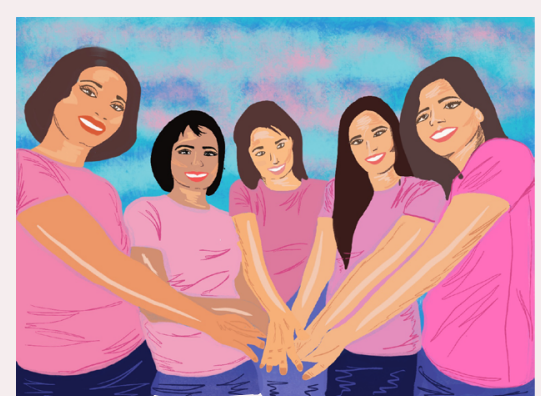

El tratamiento para el cáncer de mama puede causar cambios corporales y emocionales temporarios que se pueden aliviar con:

- Descanso apropiado

- Alimentación sana y equilibrada

- Ejercicio

- Participación en los grupos de ayuda

- Manteniendo actividades de trabajo y/o tareas cotidianas sin aislarse

\section{Recursos para más información}

Centro de tratamiento de cáncer de Sylvester Servicios de cuidado de cáncer: (305-243-4129) https://umiamihealth.org/es/sylvester-comprehensive-cancer-center/cancer-support-services/survivorship

Servicios de apoyo para el cáncer

Fundación de cáncer de mama de la Florida Recursos de apoyo: (1-877-644-3222)

https://www.floridabreastcancer.org/support-resources Recursos de apoyo

Sociedad americana de cáncer: (1-800-227-2345) https://www.cancer.org/es/cancer/cancer-de-seno/la-vidacomo-una-sobreviviente-de-cancer-de-seno/las-emocionesy-el-cancer-de-seno.html

Las emociones y el cáncer de seno

\section{Cáncer de Mama}

Lo que usted debe saber
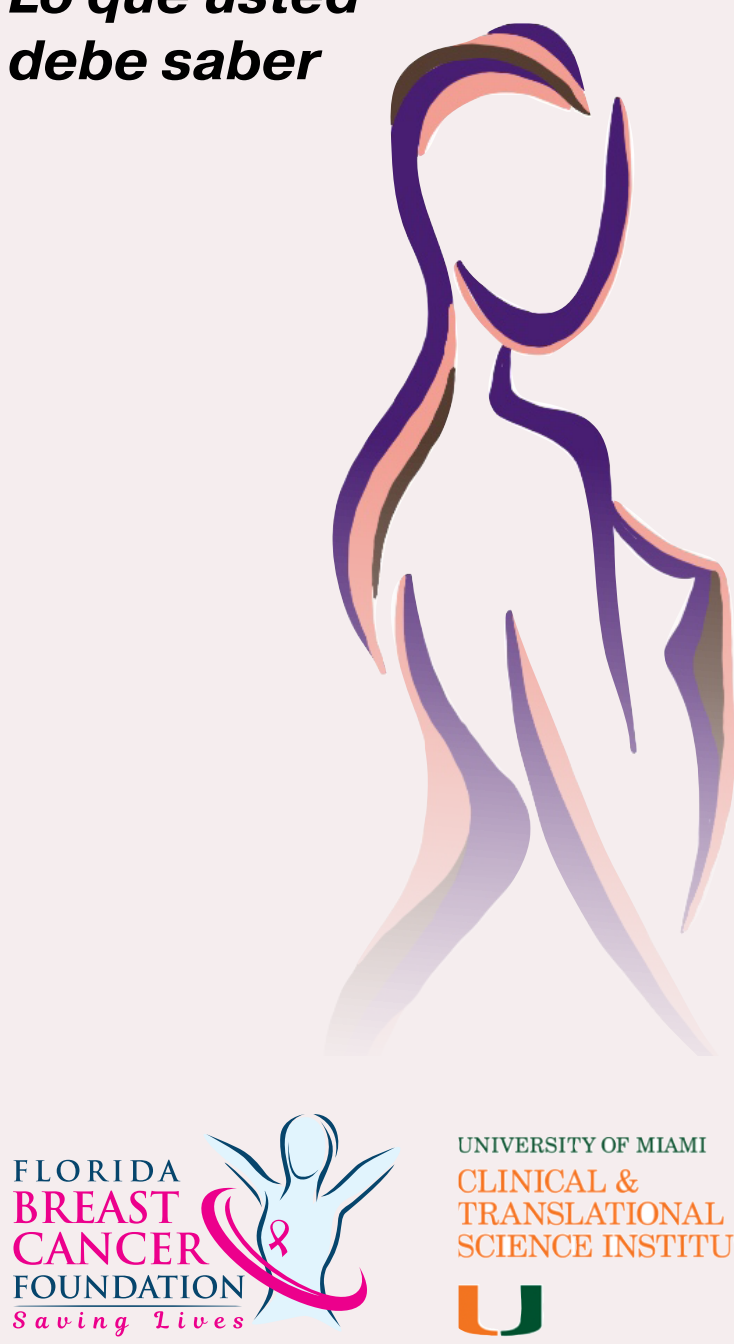

UNIVERSITY OF MIAM CLINICAL \& TRANSLATIONAI SCIENCE INSTITUTE 